\title{
Impact of Formal Financial Market Participation on Farm Size and Expenditure on Variable Farm Inputs: The Case of Maize Farmers in Ghana
}

\author{
Dadson Awunyo-Vitor, ${ }^{1}$ Ramatu M. Al-Hassan, ${ }^{2}$ and Daniel B. Sarpong ${ }^{2}$ \\ ${ }^{1}$ Department of Agricultural Economics, Agribusiness and Extension, Kwame Nkrumah University of Science and Technology, \\ Kumasi, Ghana \\ ${ }^{2}$ Department of Agricultural Economics and Agribusiness, University of Ghana, Legon, Ghana
}

Correspondence should be addressed to Dadson Awunyo-Vitor; awunyovitor@yahoo.co.uk

Received 26 August 2013; Accepted 16 September 2013; Published 12 January 2014

Academic Editors: D. Dave, M. Matsui, and M. Ransom

Copyright (C) 2014 Dadson Awunyo-Vitor et al. This is an open access article distributed under the Creative Commons Attribution License, which permits unrestricted use, distribution, and reproduction in any medium, provided the original work is properly cited.

The study examined maize farmers' participation in the formal financial market and its impact on farm size and expenditure on variable farm inputs. A multistage sampling method was used in selecting 595 maize farmers from the seven districts in Ashanti and Brong Ahafo Regions of Ghana. A structured questionnaire and interview schedule were used to elicit information from the respondents. The impact of formal financial market participation on farm size and expenditure on variable inputs was estimated using Propensity Score Matching (PSM) method. The results of the study showed that formal financial market participation has the potential to significantly increase expenditure on variable inputs by farmers and consequently use of improved technology. Therefore, formal financial market participation should be encouraged through education and promotional activities.

\section{Introduction}

The formal financial sector has been identified as important in improving productivity by making financial services available to producers in the agricultural sector. This is because informal financial services are often considered to be unsatisfactory because of extraordinarily high interest rates on credit, and savings are not sufficiently secure [1]. It is therefore assumed that participation in the formal financial market would lead to larger farm sizes and adoption of improved technology through increased expenditure on variable inputs.

In view of this, several policies have been adopted by successive governments of Ghana to improve access to financial services. These policies include liberalisation of the financial sector to increase private sector participation in the provision of financial services. The sector has now expanded from the prereform period of two foreign banks and two state owned banks with virtually no nonbank financial institutions, to include many private financial institutions. The question then is: has the expansion in the formal financial sector increased participation of farmers in the market, and if so what impact does a farmer's participation in formal financial market have on their input usage and farm size? This paper empirically examines the impact of formal financial market participation on farm size and expenditure on farm inputs by maize farmers in two regions of Ghana (Ashanti and Brong Ahafo).

The literature on impact evaluation methods is extensive. Some authors [2-4] present very useful overviews. Khandker et al. [5] have also discussed in detail different methods that are applicable for impact evaluation and the data needed for each type. In their methodological review, they stress the need to address the fundamental question of the missing counterfactual data in impact evaluation, such as assessing impact of financial services on performance indicators in a nonexperimental context.

A cross-sectional data from an observational study [5] discussed the use of the propensity score matching (PSM) approach and pointed out that this method can be used under the conditional independence assumption and common support assumption [5]. The main thrust of these 
assumptions is that all factors influencing participation are observable, and individuals with similar characteristics have an equal chance of belonging to either group (participants and nonparticipants).

Owusu and Abdulai [6] used the PSM approach to evaluate the impact of nonfarm income on food security and poverty in rural Ghana. The authors argue that participation in nonfarm activities requires a decision by the individual, which is influenced by certain individual observable factors which place them in either group. A related study [7] examined the impact of maize varieties on farm output and income levels in Mexico. In both studies, the basis for the use of PSM is that the factors which influence selection into participation (adoption) and nonparticipation (nonadoption) groups are assumed to be observable.

Mutua and Oyugi [8] have evaluated access to financial services and poverty reduction in rural Kenya using propensity score matching. The study looked at the role access to financial services could play in addressing poverty and its related problems, especially in rural areas. They observed a strong link between access to finance and poverty reduction. A policy implication arrived at from their study was that a legal and regulatory framework which takes into account the banking needs of the poor should be formulated. Owuor [9] has empirically examined the impact of microfinance on smallholder farmers in Kenya using PSM. He used multistage sampling to identify respondents. Over all, 440 farmers were interviewed in a cross-sectional survey. His findings revealed that smallholders' participation in micro-finance credit (MFC) improved their incomes by a range of between US\$ 200 to US\$ 260 per hectare in a single production period.

\section{Methodology}

2.1. Sampling and Data Collection. Multistage sampling was conducted to select 2 regions, 7 districts, and 595 farmers for the study. Selection of the regions and districts (first and second stage) was guided by the level of agricultural activities and the level of maize production using official statistics from the Ministry of Food and Agriculture (MoFA) [10].

In Ashanti Region, districts whose maize production output in 2008 exceeded 20,000 metric tonnes were selected, while in Brong Ahafo Region, the 5 districts which had a minimum of 27,000 metric tonnes each of maize output in 2008 were selected for the study. A third stage of sampling involved identifying and listing maize farmers in the operational areas of the extension agents. Selection of respondents was guided by their involvement in maize production. A total of 595 maize farmers from the study area were sampled for the study.

A questionnaire was administered to the sampled farmers. The survey questionnaire contained detailed sections on demographic and socioeconomic characteristics of the farmers, household characteristics, variable input usage, farm size, and formal financial market participation.

2.2. Theoretical and Analytical Framework. Formal financial market participation is considered in terms of usage of any of the formal financial services or combination of these services by the respondents. Respondents are considered financial market participants if they responded yes to the question "have you used any financial services within the formal financial market segment?" We adopted and modified a method used by [7] to evaluate the impact of formal financial market participation on farm size and expenditure and on variable inputs as a proxy for technology adoption.

Becerril and Abdulai [7] employed PSM to evaluate the marginal impact of improved maize varieties on poverty in Mexico. Rosenbaum and Rubin [11] pioneered this method followed by many other improvements and applications in works by [12-14]. Propensity Score is defined as the conditional probability of participation given preparticipation characteristics. The main basis for the use of PSM is that participation and nonparticipation decisions may not be random but rather selective and depending on preparticipation variables: the estimation of the effect of participation may be biased by the existence of selectivity bias or confounding factors. For example, in order to evaluate the impact of financial market participation on farm size and expenditure on variable input, it is necessary to draw a counterfactual scenario about the productivity variables of farmers who participated in the formal financial market. This group of respondents is referred to as the treated group of farmers. The counterfactual would then be compared with farm size and expenditure on variable inputs of the treated (those who participated in formal financial market) in order to evaluate the impact of formal financial market participation on farm size and expenditure on variable inputs. For the treated, their counterfactual is the farm size and expenditure they incurred on variable inputs when they did not participate in the formal financial market segment. While for the untreated (farmers who did not participate in formal financial market) their counterfactual is their farm size and expenditure on variable input when they participate in the formal financial market segment. If we use $\varphi$ to represent the impact of financial market participation on one of the outcome variables say farm size, then

$$
\varphi=Y_{1}-Y_{0}
$$

where $Y_{1}$ and $Y_{0}$ denote farm sizes of the respondents when they participated in the financial market and the counterfactual, respectively. The average treatment effect (ATE) of financial market participation can be calculated as

$$
\mathrm{ATE}=E(\delta)=E\left(Y_{1}-Y_{0}\right),
$$

where $E(\cdot)$ represents the average or expected farm size. The impact of treatment on farm size of the farmers who participated in the financial market (treated) can be estimated as

$$
\operatorname{ATT}=E\left(Y_{1} \mid D=1\right)-E\left(Y_{0} \mid D=1\right),
$$

where ATT represents Average Treatment effect on the treated and $D$ denotes the formal financial market participation indicator which equals one (1) if the farmer participated in the formal financial market and zero (0) otherwise. $E\left(Y_{0} \mid\right.$ $D=1)$ is the mean farm size of treated in absence of the 
treatment, that is, counterfactual farm size. In the case of nonparticipant (untreated or control) group of farmers, their average farm size can be estimated as

$$
\mathrm{ATU}=E\left(Y_{1}-Y_{0} \mid D=0\right)
$$

where ATU is the Average Treatment effect on the untreated. The estimation of ATT and ATU clearly depends on the counterfactual levels of farm size of the two groups, treated and control $\left\{E\left(Y_{0} \mid D=1\right)\right.$ and $\left.\left(Y_{0} \mid D=0\right)\right\}$, respectively, as explained above. In nonexperimental studies such as ours, it is impossible to assess the counterfactual farm sizes of the two groups of respondent formal financial market participants (treated) and nonparticipant (untreated or control) groups. It is possible to use the farm size of nonparticipants as a counterfactual for participants or the treated. However, this may lead to a biased estimate of the impact (ATT) as a result of selection bias (Rosenbaum and Rubin, 1983) as follows:

$$
\Delta=E\left(Y_{1} \mid D=1\right)-E\left(Y_{0} \mid D=0\right) .
$$

Through expansion and rearrangement, we have

$$
\begin{gathered}
\Delta=E\left(Y_{1} \mid D=1\right)-E\left(Y_{0} \mid D=1\right) \\
+E\left(Y_{0} \mid D=1\right)-E\left(Y_{0} \mid D=0\right), \\
\Delta=\mathrm{ATT}+E\left(Y_{0} \mid D=1\right)-E\left(Y_{0} \mid D=0\right), \\
\Delta=\mathrm{ATT}+\mathrm{SB}, \\
\mathrm{ATT}=\Delta-\mathrm{SB},
\end{gathered}
$$

where SB is selection bias which arises as a result of unobservable characteristics influencing selection of respondents into treatment and control groups, respectively. If $\mathrm{SB}=0$ then the difference between the average observed farm size of treated and control groups of farmers would be given as

$$
\mathrm{ATT}=E(Y \mid D=1)-(Y \mid D=0) .
$$

However if SB is not equal to zero then there exists selection bias; thus the estimated ATT would not be the difference in the average observed farm size of the treated and untreated (nonparticipants).

It is possible that hard working farmers may be the ones who participated in formal financial market due to these institutions' screening process; thus $\mathrm{SB} \neq 0$. Hence farmers who participated in formal financial market may have larger farm sizes even if they did not participate in the formal financial market compared to nonparticipants. As a result, average farm size of the untreated group is not a good comparison for the counterfactuals of the treated group in estimating the impact of formal financial market participation on farm size.

Therefore, [11] suggested the use of the propensity score matching approach as a way to correct for the existence of these confounding factors based on the idea that the bias is reduced when the comparison is performed using participants and control group of farmers who are as similar as possible [5]. This approach is based on the idea that by matching the outcome variables of treated and control respondents who are similar in observable characteristics, selection bias would be eliminated.

The PSM method summarizes preparticipation characteristics into a single index known as the propensity score, which makes matching feasible. The propensity score is a conditional probability estimator, and any discrete choice model such as logit or probit can be used as they yield similar results [14]. Thus, the PSM approach follows two steps; first, either the logit or probit model is used to estimate the probability (propensity score) of programme participation, in this case financial market participation, using observable characteristics which influence participation in formal financial market. In this study the logit model is specified as

$$
\begin{aligned}
P(X) & =P(D=1 \mid X) \\
& =F\left(\beta_{1} X_{1}+\cdots \beta_{i} X_{i}\right) \\
& =F(X \beta) \\
& =e^{X \beta},
\end{aligned}
$$

where $F(\cdot)$ denotes response probability which strictly ranges between zero and one, $X$ is a vector of all observable characteristics (Covariates) which influence formal financial market participation, and $\beta$ is the parameter of interest to be estimated.

This model predicts the probability (propensity score) of formal financial market participation. Given that the propensity score is a balancing score, the probability of formal financial market participation conditional on $X$ will lead to distribution of farmers' covariates $X$, such that these covariates will be the same for treatment and control groups. Assuming that all information relevant to formal financial market participation and farm size are observable, then the propensity score will produce valid matches which can be used to estimate impact (ATT) of formal financial market participation on farm size and expenditure on variable input at the second stage. This is done by matching the two groups of respondents on the basis of the predicted propensity scores as follows:

$$
\begin{aligned}
\operatorname{ATT}=\{ & \left(E\left(Y_{1} \mid D=1 \cdot E(P(X))\right)\right) \\
& \left.-E\left(Y_{0} \mid D=1 \cdot E(P(X))\right)\right\},
\end{aligned}
$$

where $E(P(X))$ denote the expectation with respect to the distribution of the propensity score in the entire population and $E\left(Y_{1} \mid D=1, P(X)\right), E\left(Y_{0} \mid D=1\right)$ are as defined above under (3).

Three different matching algorithms which involve tradeoffs in terms of bias and efficiency are used to estimate ATT. These matching estimators are Nearest Neighbour, Radius, and Kernel Matching methods and are all conditional on the propensity score. Nearest Neighbour Matching (NNM) selects the control group with the smallest distance in propensity score to the treated group (farmers who access financial services). Generally, this is done with replacement, and it works well once the distribution of the propensity score of both groups (control and treated) is similar. However, 
NNM may lead to poor matches when the nearest neighbours are far away.

Radius Matching (RM) or Calliper involves all neighbours with a maximum propensity score distance. This is normally defined a priori, and it corresponds to the common support assumption. Radius matching also helps to avoid poor matches which may arise through matching too distant neighbours [15]. Kernel-Based Matching (KM) was recommended by [16]. This is a nonparametric estimator that includes all respondents of the underlying sample of control group and weighs more distant observed characteristics among both groups (control and treated) down. Hence it indicates lower variance. Caliendo and Kopenig [14] noted that poorer matches could be obtained. The Kernel-based estimator of the ATT describes the mean difference in outcome while the matched outcome is given by the Kernelweighted average of the outcome of the control group of farmers.

The PSM model works under two assumptions, namely, the conditional independence assumption and the common support or the balancing assumption. The conditional independence assumption postulates that all the covariates must be independent of participation. This means that the selection of farmers into both groups (treatment and control groups) is exclusively based on observable covariates $X$ which influence the propensity score. In this case, farm size and expenditure on variable inputs of participants (treated) and nonparticipants (control group) are assumed to be independent of the treatment, conditional on observable characteristics or covariates $X$, respectively. Thus respondents' participation and nonparticipation decision is exclusively based on observable covariate $X$. The balancing assumption or the common support assumption (CSA) postulates that participation is shaped by preparticipation characteristics. Thus, this assumption rules out the phenomenon of perfect predictability of financial market participation $(D=1)$ given covariates $X$. This ensures that farmers with identical observable characteristics or covariates $(X)$ have a positive probability of belonging to a particular group [16].

Good quality matches are those whose covariates are conditioned after the estimation of the propensity score and which are able to balance the distribution of the relevant variables between the treated and controlled respondents. For the standardized bias approach proposed by [11], the quality of matches is assessed by comparing the situation before and after matching to check if there remain any differences after conditioning on the propensity score. Sianesi [17] has also recommended an additional assessment of the matching quality which requires the reestimation of the propensity score of matched participants and matched nonparticipants. The matching procedure is expected to balance the covariates very well if the pseudo- $R^{2}$ after matching is fairly low, while the probability of the F-statistics is not significantly different from zero.

Furthermore, following [18] an appropriate control strategy of hidden bias is to examine the sensitivity of significance levels. It is important to assess the sensitivity of the estimated participating effect because this explained what happens when there is hidden bias. The symbol $e^{\gamma}$ is used to present a measure of the degree of departure from a PSM result that is free from hidden bias [18]. Thus several values of $e^{\gamma}$ are calculated to test the sensitivity of the significance level. This test helps to identify the critical impact level at which significance would be lost. This represents the level of unobservable covariate at which the inference about the treatment effect will be undermined [19]. In this study, the quality of the matches is evaluated by using the approach recommended by [17], and the sensitivity of significance levels was examined by using a method suggested by [18]. The first step in the PSM approach is the estimation of the participation model using a binary choice model. In this study the logit model was used to estimate probability of formal financial market participation or use of formal financial services.

The empirical model is specified as

$$
\begin{aligned}
\text { PART }= & \beta_{0}+\beta_{1} \text { GEN }+\beta_{2} \text { YEDU }+\beta_{3} \text { VALMOUTPU } \\
& +\beta_{4} \text { OATIV }+\beta_{5} \text { HSIZ }+\beta_{6} \text { TASET } \\
& +\beta_{7} \text { PROXIFA }+\beta_{8} \text { LenProFOR }+\beta_{9} \text { FSIZE }+e .
\end{aligned}
$$

\section{Definition of Variables Used in the Logit Model}

3.1. Dependent Variable: Participation in Formal Financial Market (PART). A dummy variable is used as the dependent variable as "use of formal financial services." This variable reflects respondent's use of formal financial services. It is specified as 1 if the respondent participates or uses any of the services provided by formal financial institutions and 0 otherwise.

\subsection{Independent Variables}

3.2.1. Gender (GEN). The likelihood of use of saving, credit, and money transfer services is assumed to be lower among female farmers. Relatively, female farmers are often poorer than male farmers. World Bank [20, 21] indicated that the female gender in the individual, household, and wider community and national context are affected by financial, economic, cultural, political, and legal obstacles which affect their demand for financial services.

Gender classification is important in this type of analysis because in Ghana as in many African societies, men and women have different levels of responsibilities and engage in different economic activities. Even if they engage in the same economic activities, it is at varying degrees of operation which have different implications on their use of financial services. The gender of the respondent is specified as a dummy variable which takes the value of 1 if the respondent is male and 0 otherwise. It is hypothesised that male farmers are more likely to participate in formal financial market compared to female farmers. 
3.2.2. Years of Schooling (YEDU). Respondents who have attained higher educational levels are expected to have more exposure to the financial institution's policies regarding use of financial services. The higher the educational level is the more likely the farmer would be able to understand the needs of the financial institution in terms of requirement for access to their services. Therefore, it is hypothesized that education would have a positive relationship with use of services provided by formal financial institutions. Steiner [22] found a positive and significant relationship between higher education and use of formal financial services in Ghana. In this study we use the number of years of schooling to represent level of education.

3.2.3. Previous Year's Maize Income (VALPUT). The value of maize harvested is an important factor that would determine a farmer's use of services provided by formal financial institutions because this is a major source of their income. Where the value of maize harvested is low, the farmer has limited resources to save hence could not participate in the formal financial market by saving and may not be able to access credit as most institutions use savings as collateral for granting loans. Alternatively with a higher income from maize, a farmer may be able to save and demand credit therefore is more likely to participate in a formal financial market. This variable is specified as total value of maize sales from previous year's harvest, and it is hypothesised to have a positive effect on the demand for financial services.

\subsubsection{Off-Farm Income Generating Activities (OATIV).} Farmers may engage in off-farm income generating activities. Some activities require large amounts of capital and offer higher returns compared to others. In addition, formal financial institutions develop products which fit the revenue and expenditure cycles of off-farm income activities which encourage use of formal financial services. Therefore, use of formal financial services is assumed to have a positive relationship with engagement in off-farm income generating activities. This variable is specified as a dummy variable which takes the value of 1 if the farmer has a secondary income source and 0 otherwise.

3.2.5. Farmer's Household Size (HSIZ). The size of the household is assumed to positively influence the likelihood of using formal financial services. This is because larger households have more household members thus potentially may have higher consumption expenses which may affect their ability to save. Levels of saving tend to influence access to credit. Also larger households may have members who might occasionally be living outside their permanent residence and send money to or receive money from the household. For example, households may have a member in senior high school, whose fees may be paid through a formal financial institution. Chen and Chivakul [23] found family size to be a significant variable which influenced credit demand for household in Bosnia and Herzegovina. This variable is measured as the number of individual household members taken care of by the respondents. This variable is expected to have a negative effect on formal financial market participation.
3.2.6. Farmer's Household Assets (TASET). The value of the farmer's household assets is estimated as the sum of the resale value of household or domestic assets measured in Ghana Cedis $(\mathrm{GH})$ ). This is used as a proxy for respondent's wealth status in line with [24]. It is expected that the higher the value of the asset is, the more likely farmers will participate in formal financial market by using saving and credit facilities as these assets can be used as collateral to secure loans which would support income generation and consequently savings. Therefore value of household asset is expected to have a positive effect on participation in formal financial market.

\subsubsection{Proximity to Formal Financial Institution (PROXIFA).} Farmers who live far from financial institutions are less likely to contact the financial institution easily for more information than those who live close by. Thus it is assumed that a farmer who lives at a distance of less than $2 \mathrm{~km}$ (walking distance) to a financial institution is more likely to use services provided by the institution because of lower transactions cost. This variable is specified as a dummy and takes the value of 1 if the farmer perceived the distance to be far, that is, beyond a walking distance $(2 \mathrm{Km})$ to the nearest formal financial institution and 0 otherwise.

3.2.8. Farmers' Perception of Operational Modalities of Financial Institution (OPMO). Farmers pass through different processes to use formal financial services which are operational modalities of the institution. Depending on the institution, some of these processes can be time consuming and difficult to understand. Farmers may prefer to use financial services if they perceive operational modalities to be satisfactory. This variable is specified as a dummy variable which takes a value 1 if farmer perceive savings processes and lending procedures as cumbersome or unsatisfactory and 0 otherwise.

3.2.9. Farm Size (FSIZE). Farm size is measured in hectares and used as a proxy for the scale of operation, and it can also be used by lenders to estimate expected income of the farmer and therefore earning capacity. Farmers with large farm sizes are expected to increase the use of formal financial services as it influences savings and consequently credit.

\section{Results and Discussion}

4.1. Participation in Formal Financial Market. The data has been disaggregated into farmers who participated in formal financial market only, those who participated in informal financial market only, and those who participated in both formal and informal financial market. In all, $41 \%$ of the respondents participated in the formal market segment only while $13 \%$ used the informal market segment only. About eleven percent of the respondents used both market segments and close to $34 \%$ used neither formal nor informal financial intermediaries (see Table 1).

4.2. Factors Influencing Formal Financial Market Participation. The estimated coefficients of the logit model, along with the levels of significance and marginal effects, are presented 
TABLE 1: Financial market participation among the sample.

\begin{tabular}{lcc}
\hline Institution & Frequency & Percentage \\
\hline Formal & 243 & 40.84 \\
Informal & 79 & 13.28 \\
Both formal and informal & 70 & 11.76 \\
None & 203 & 34.12 \\
\hline Total & 595 & 100.00 \\
\hline
\end{tabular}

Source: Survey data.

in Table 2. The likelihood ratio statistics as indicated by chisquare statistics are highly significant $(P<0.00001)$, suggesting that the model has a strong explanatory power. The logit regression gave $P$ value for Hosmer and Lemeshow goodness-of-fit test as 0.8602 which suggests that the model fits reasonably well. Given these goodness of fit measures, it is concluded that the logit model used has integrity and is appropriate.

The coefficient of education is positive and statistically significant at $1 \%$ level of significance. This implies that farmers with higher level of education are more likely to participate in formal financial market. This might be due to the fact that they can read and write hence understand benefit of using formal financial services and also are able to follow the procedures of the financial institution required for use of their services. A unit increase in number of years of schooling would result in a $1.72 \%$ increase in the likelihood of respondents participating in the formal financial market. The previous year's maize income has a positive and significant effect on participation in the formal financial market. This implies that if farmers earn more from maize production activities, they are more likely to keep their excess income with formal financial institution. A cedi increase in maize income increases the likelihood of using services of a formal financial institution by $1.83 \%$.

Engagement in off-farm income generating activities significantly increases the likelihood of respondents participating in the formal financial market. This is because farmers who engage in off-farm income generating activities tend to generate additional income, which increases their demand for savings. This improves their savings and increases their account balance thereby increasing their demand for credit. Engagement in off-farm income generating activities increases the probability of using formal financial services by $11 \%$. A farmer's total assets also have a positive effect on their use of formal financial services. This result indicates that wealthy farmers are more likely to participate in formal financial market.

The coefficient of a farmer's perception on proximity to the nearest formal financial institution is negative and significant at $1 \%$. The result indicates that farmers who perceive that the distance between their residence and the location of the formal financial institution to be too far are less likely to participate in the formal financial market. Specifically farmers who perceive the distance to be far are $17.9 \%$ less likely to use services of formal financial institutions. This may be attributed to the fact that they would incur higher costs to transact business with the institution.
As can be observed in Table 2, the coefficient of operational modalities is positive and significant at $1 \%$. Farmers who perceive operational modalities of formal financial institutions to be satisfactory are $37 \%$ more likely to use their services compared to their counterparts who perceive the operational modalities as unsatisfactory.

Farm size is related positively to participation in formal financial market. The coefficient is statistically significant at $5 \%$ level of significance. Based on the marginal effect, a hectare increase in farm size is likely to increase probability of farmer participating in formal financial market by $12.5 \%$ (Table 2).

\subsection{Impact of Formal Financial Market Participation on Farm} Size and Expenditure on Variable Inputs. Nearest Neighbour, Radius, and Kernel-based matching algorithms were used for the matching. The results of the propensity score matching on the impact of formal financial market participation on farm size and expenditure on variable inputs per hectare are presented in Table 3. All the matches gave similar results. The nearest neighbour matching estimate of the impact of formal financial market participation on farm size recorded an increase of about 0.11 hectare. However, this increase is statistically insignificant. In the case of expenditure on variable inputs, farmers who participated in the formal financial market recorded higher expenditure than nonparticipants (GHć 85.18), and this is significant at the $1 \%$ level. In the case of calliper or radius matching, we considered neighbours with a calliper of 0.01 .

The result shows a 0.99 hectare increase in farm size, but this is statistically not significant. However, there is a GHć79.42 increase in expenditure on variable inputs per hectare as a result of formal financial market participation by the respondents and is statistically significant at $1 \%$. These results support the findings of [9] that farmers in Kenya who participated in microfinance programme had significantly higher productive income which can be attributed to higher input usage.

With regard to kernel-based matching algorithm, each participant is matched with a weighted average of all nonparticipants with weights that are inversely proportional to the distance between the propensity score of the participants and nonparticipants. In this study, we used a smoothening parameter of 0.06 . The effect of formal financial market participation on farm size and expenditure on variable inputs per hectare shows an increase of 0.41 hectare and GHć 82.58, respectively. However, only expenditure on variable inputs is statistically significant at $1 \%$ level of significance. All the matching techniques produce consistent estimates of the effect of formal financial market participation on farm size and expenditure on variable inputs.

Table 4 presents results from covariate balancing tests before and after matching which gives an indication of matching quality. The results show substantial reduction in absolute bias for all the outcome variables for the three matching algorithms. As indicated in Table 3, the mean bias after matching lies below the $20 \%$ level suggested by [11]. 
TABLE 2: Logit model to predict the probability of participating in formal financial market conditional on selected observables characteristics. Dependent variable: participation or access to formal financial services $(Y=1)$.

\begin{tabular}{lcc}
\hline Covariates & Odds Ratio & Marginal Effect \\
\hline GEN gender of respondents & 1.3387 & 0.0709 \\
YEDU years of schooling & $1.0742^{* * *}$ & 0.0172 \\
VALPUT previous year's maize income & $1.0285^{* *}$ & 0.0183 \\
TASET total asset & $1.0003^{* *}$ & 0.0007 \\
OATIV engaged in off-farm income generating & $1.5863^{* *}$ & 0.1125 \\
activities & $2.0473^{* * *}$ & 0.1757 \\
ACOM level of maize commercialisation & $-2.2250^{* * *}$ & -0.1799 \\
PROXI proximity to financial institution & $7.1746^{* * *}$ & 0.3791 \\
OPMO operational modalities & $2.0214^{* *}$ & 0.1256 \\
FSIZE farm size & & \\
\hline
\end{tabular}

Number of obs $=577$

$\operatorname{LR} \chi^{2}(14)=168.41$

Prob $>\chi^{2}=0.0000$

Pseudo $R^{2}=0.2114$

${ }^{*} P<0.1 ;{ }^{* *} P<0.05 ;{ }^{* * *} P<0.01$

TABLE 3: Estimated impact of formal financial market participation on farm size and expenditure on variable inputs per hectare.

(a) Nearest neighbour matching (NNM)

\begin{tabular}{lccc}
\hline Outcomes & $\begin{array}{c}\text { Average treatment } \\
\text { effect (ATE) }\end{array}$ & $\begin{array}{c}\text { Average treatment } \\
\text { effect on untreated } \\
\text { (ATU) }\end{array}$ & $\begin{array}{c}\text { Average treatment } \\
\text { effect on the treated } \\
\text { (ATT) }\end{array}$ \\
\hline Farm size & 5.993 & 5.882 & $0.111(0.21)$ \\
Expenditure on variable inputs & 190.826 & 105.642 & $85.184^{* * *}(4.93)$ \\
No. of observations & 218 & 180 & \\
\hline
\end{tabular}

(b) Radius matching (RM) with a calliper of 0.01

\begin{tabular}{lccc}
\hline Outcomes & $\begin{array}{c}\text { Average treatment } \\
\text { effect (ATE) }\end{array}$ & $\begin{array}{c}\text { Average treatment } \\
\text { effect on untreated } \\
\text { (ATU) }\end{array}$ & $\begin{array}{c}\text { Average treatment } \\
\text { effect on the treated } \\
\text { (ATT) }\end{array}$ \\
\hline Farm size & 6.0584 & 5.143 & $0.985(0.66)$ \\
Expenditure on variable inputs & 192.519 & 113.095 & $79.423^{* * *}(3.17)$ \\
No. of observations & 190 & 174 & \\
\hline
\end{tabular}

(c) Kernel-based matching (KBM) using smoothening parameter of 0.06

\begin{tabular}{|c|c|c|c|}
\hline Outcomes & $\begin{array}{l}\text { Average treatment } \\
\text { effect (ATE) }\end{array}$ & $\begin{array}{l}\text { Average treatment } \\
\text { effect on untreated } \\
\text { (ATU) }\end{array}$ & $\begin{array}{l}\text { Average treatment } \\
\text { effect on the treated } \\
\text { (ATT) }\end{array}$ \\
\hline Farm size & 6.127 & 5.721 & $0.406(0.65)$ \\
\hline Expenditure on variable inputs & 192.083 & 109.502 & $82.581^{* * *}(3.02)$ \\
\hline No. Of observations & 227 & 190 & \\
\hline
\end{tabular}

$t$-statistics are in parenthesis.

Source: own calculations.

${ }^{* * *} P<0.01$.

This indicates that the variables were significantly balanced as a result of the propensity score matching procedure. In addition, the pseudo- $R^{2}$ s after matching are fairly low with none of the $F$-statistics being significantly different from zero, suggesting that the proposed specification of the propensity score is fairly successful in terms of balancing the distribution of covariates between the two participants and nonparticipants [17].

Furthermore, following [18] the sensitivity of significance levels were examined. Here, several values of $\mathrm{e}^{\gamma}$ bounds are calculated on the significance level, and the null hypotheses of no effect of participation on potential outcomes, farm 
TABLE 4: Indicators of matching quality before and after matching.

\begin{tabular}{|c|c|c|c|c|c|c|c|c|}
\hline $\begin{array}{l}\text { Matching } \\
\text { algorithm }\end{array}$ & $\begin{array}{l}\text { Outcome } \\
\text { indicator }\end{array}$ & $\begin{array}{c}R^{2} \\
\text { unmatched }\end{array}$ & $\begin{array}{c}R^{2} \\
\text { matched }\end{array}$ & $\begin{array}{c}P \text { value } \\
\text { unmatched }\end{array}$ & $\begin{array}{l}P \text { value } \\
\text { matched }\end{array}$ & $\begin{array}{c}\text { Mean absolute } \\
\text { bias } \\
\text { unmatched }\end{array}$ & $\begin{array}{c}\text { Mean } \\
\text { absolute } \\
\text { bias matched }\end{array}$ & $\begin{array}{l}\text { Absolute bias } \\
\text { reduction }\end{array}$ \\
\hline \multirow{2}{*}{$\begin{array}{l}\text { Nearest } \\
\text { neighbour }\end{array}$} & Farm size & 0.209 & 0.021 & 0.000 & 0.399 & 21.6 & 7.6 & 64.7 \\
\hline & $\begin{array}{c}\text { Expenditure on } \\
\text { variable inputs } \\
\text { per hectare }\end{array}$ & 0.209 & 0.020 & 0.000 & 0.308 & 8.2 & 12.1 & 47.8 \\
\hline \multirow[b]{2}{*}{ Calliper } & Farm size & 0.209 & 0.017 & 0.000 & 0.555 & 21.6 & 5.8 & 73.0 \\
\hline & $\begin{array}{c}\text { Expenditure on } \\
\text { variable inputs } \\
\text { per hectare }\end{array}$ & 0.209 & 0.018 & 0.000 & 0.456 & 8.2 & 11.6 & 40.8 \\
\hline \multirow{2}{*}{$\begin{array}{l}\text { Kernel base } \\
\text { matching }\end{array}$} & Farm size & 0.213 & 0.026 & 0.000 & 0.268 & 21.6 & 5.6 & 73.0 \\
\hline & $\begin{array}{c}\text { Expenditure on } \\
\text { variable inputs } \\
\text { per hectare }\end{array}$ & 0.209 & 0.020 & 0.000 & 0.308 & 8.2 & 12.1 & 47.5 \\
\hline
\end{tabular}

Source: author's calculations.

TABLE 5: Sensitivity analysis with Rosenbaum's bounds on probability values on farm size and expenditure on variable inputs.

\begin{tabular}{|c|c|c|c|c|c|}
\hline & \multicolumn{5}{|c|}{ Upper bounds on the significance level for different values of $\mathrm{e}^{\gamma}$} \\
\hline & $\mathrm{e}^{\gamma}=1.25$ & $\mathrm{e}^{\gamma}=1.5$ & $\mathrm{e}^{\gamma}=1.75$ & $\mathrm{e}^{y}=2$ & \\
\hline \multicolumn{6}{|c|}{ Using the single closest neighbour } \\
\hline Farm size & 0.0001 & 0.0072 & 0.0871 & 0.327 & 0.6324 \\
\hline Expenditure on variable inputs & $<0.0001$ & $<0.0001$ & 0.0018 & 0.0211 & 0.1009 \\
\hline \multicolumn{6}{|c|}{ Using all neighbours within a calliper of 0.01} \\
\hline Farm size & 0.0005 & 0.0255 & 0.1884 & 0.505 & 0.785 \\
\hline Expenditure on variable inputs & $<0.0001$ & $<0.0001$ & 0.0015 & 0.0171 & 0.0832 \\
\hline \multicolumn{6}{|c|}{ Using a biweight kernel function and a smoothing parameter of 0.06} \\
\hline Farm size & 0.0001 & 0.012 & 0.1254 & 0.4131 & 0.7202 \\
\hline Expenditure on variable inputs & $<0.0001$ & $<0.0001$ & 0.0001 & 0.003 & 0.023 \\
\hline
\end{tabular}

Source: author's calculations.

size, and expenditure on variable inputs tested, respectively, using the three introduced matching algorithms. Table 5 presents the result of the sensitivity analysis on farm size and expenditure on variable inputs.

Overall, robustness of the results produced by Rosenbaum's bounds are quite similar. Kernel-based matching produces the most robust treatment effect estimates with respect to hidden bias especially in the case of expenditure on variable inputs. Matched pairs might differ $\left(\mathbf{e}^{y}=2\right)$ in unobservable characteristics, while the impact of participation on expenditure on variable inputs would be still significant at a level of $5 \%$.

The same expenditure on variable inputs is robust to hidden bias up to an influence of $\mathbf{e}^{\gamma}=2$ at a significance level of $10 \%$ following the radius matching approach. Also the nearest neighbour matching is robust to selection bias unobservable characteristics up to an impact level of $\mathbf{e}^{\gamma}=1.75$ and $\mathrm{e}^{\gamma}=2$, respectively. The estimated treatment effects on farm size are sensitive to hidden bias, at a smaller unobservable impact level of $\mathbf{e}^{\gamma}=1.5$. Nevertheless, it has to be considered that these sensitivity results are worst-case scenarios, even though they indicate information about uncertainty within the matching estimators of treatment effects [18].

\section{Conclusion and Policy Implications}

The results from the logit model indicate that farmers' socioeconomic characteristics such as education, previous year's maize income, engagement in off-farm income generating activities, and farm size significantly influence their formal financial market participation positively. Thus improvement in the farmers' income levels through off-farm income generating activities and stable producer prices for maize would encourage farmers' participation in formal financial market or use of formal financial services.

Governmental and Nongovernmental Organisations that work to empower farmers' livelihood should train the farmers in off-farm income generating activities. This will encourage farmers' participation in formal financial market. Farm income improvement policy in terms of adequate remunerations for farmers (stable producer prices) is also an important policy option for increasing formal financial market participation.

Also, farm size expansion and a maize commercialisation policy will improve farmers' participation in financial services. Furthermore, availability of formal financial institution and use of friendly operational modalities will improve formal financial market participation by farmers. Thus, formal 
financial institutions should adapt their savings and lending modalities to the needs of the farmers (i.e., making it less cumbersome).

The results of the PSM analysis showed that farmers who participated in the formal financial market tended to spend more on variable inputs than nonparticipants. They also had higher farm sizes as compared with nonparticipants (albeit not statistically significant). Therefore, formal financial market participation should be encouraged through education and promotional programmes by formal financial institutions.

\section{Conflict of Interests}

The authors declare that there is no conflict of interests regarding the publication of this paper.

\section{References}

[1] S. R. Khandker and R. R. Faruqee, "The impact of farm credit in Pakistan," Agricultural Economics, vol. 28, no. 3, pp. 197-213, 2003.

[2] E. Duflo, R. Glennerster, and M. Kremer, "Using randomization in development economics research," Handbook of Development Economics, vol. 4, pp. 25-39, 2008.

[3] M. Ravallion, "Bailing out the world's poorest," Challenge, vol. 52, no. 2, pp. 55-80, 2008.

[4] R. Blundell and M. C. Dias, "Evaluation methods for nonexperimental data," Fiscal Studies, vol. 21, no. 4, pp. 427-468, 2000.

[5] S. R. Khandker, G. B. Koolwal, and H. A. Samad, Handbook on Impact Evaluation: Quantitative Methods and Practices, The world Bank, Washington, DC, USA, 2010.

[6] V. Owusu and A. Abdulai, "Non-farm Work and Food Security Among Farm Households in Northern Ghana," nonfarm_northern-ghana, 2009, http://www.pegnet.ifw-kiel.de/ activities/research/.

[7] J. Becerril and A. Abdulai, "The impact of improved maize varieties on poverty in Mexico: a propensity score-matching approach," World Development, vol. 38, no. 7, pp. 1024-1035, 2010.

[8] J. M. Mutua and L. N. Oyugi, "Access to financial services and poverty reduction in rural Kenya," NEPRU Working Paper 108, 2006.

[9] G. Owuor, "Is micro-finance achieving its goal among smallholder farmers in Africa? Empirical evidence from Kenya using propensity score matching," in Proceedings of the 25th International Conference of Agricultural Economists, Beijing, China, August 2009.

[10] Ministry of Food and Agriculture, Agriculture in Ghana Facts and Figures, MoFA Ghana, 2009.

[11] P. R. Rosenbaum and D. B. Rubin, "The central role of the propensity score in observational studies for causal effects," Biometrika, vol. 70, no. 1, pp. 41-55, 1983.

[12] R. H. Dehejia and S. Wahba, "Causal effects in nonexperimental studies: reevaluating the evaluation of training programs," Journal of the American Statistical Association, vol. 94, no. 448, pp. 1053-1062, 1999.

[13] S. O. Becker and A. Ichino, "Estimation of average participation effects based on propensity scores," The Stata Journal, vol. 2, no. 4, pp. 358-377, 2002.
[14] M. Caliendo and S. Kopeinig, "Some practical guidance for the implementation of propensity score matching," Journal of Economic Surveys, vol. 22, no. 1, pp. 31-72, 2008.

[15] J. A. Smith and P. E. Todd, "Does matching overcome LaLonde's critique of nonexperimental estimators?" Journal of Econometrics, vol. 125, no. 1-2, pp. 305-353, 2005.

[16] J. Heckman, R. LaLonde, and J. Smith, "The economics and econometrics of active labor market programs," in Handbook of Labor Economics, O. Ashenfelter and D. Card, Eds., vol. 3, pp. 1865-2097, Elsevier, Amsterdam, The Netherlands, 1999.

[17] B. Sianesi, "An evaluation of the active labour market programmes in Sweden," The Review of Economics and Statistics, vol. 86, no. 1, pp. 133-155, 2004.

[18] P. R. Rosenbaum, Observational Studies, Springer, New York, NY, USA, 2002.

[19] T. A. DiPrete and M. Gang, "Assessing bias in the estimation of causal effects: rosenbaum bounds on matching estimators and instrumental variables estimation with imperfect instruments," Sociological Methodology, vol. 34, pp. 271-310, 2004.

[20] World Bank, Finance for All? Policies and Pitfalls in Expanding Access, World Bank, Washington, DC, USA, 2005.

[21] T. Jappelli, "Who is credit constrained in the U.S. economy," Quarterly Journal of Economics, vol. 105, pp. 219-234, 1990.

[22] S. Steiner, Determinants of the Use of Financial Services in Rural Ghana: Implications For Social Protection, Brooks World Poverty Institute, University of Manchester, 2008.

[23] C. K. Chen and M. Chivakul, "What drives household borrowing and credit constraints? Evidence from bosnia Herzegovnia," IMF Working Paper 08(202), 2008.

[24] M. A. Y. Rahji and S. B. Fakayode, "A multinomial logit analysis of agricultural credit rationing by commercial banks in Nigeria," International Research Journal of Finance and Economics, vol. 1, no. 24, pp. 90-100, 2009. 